\title{
Impact of Sunitinib on Human Thyroid Cancer Cells
}

\author{
Jirka Grosse ${ }^{a}$ Elisabeth Warnke ${ }^{b}$ Fabian Pohlc Nils E. Magnusson ${ }^{\text {de }}$ \\ Markus Wehland ${ }^{\mathrm{b}}$ Manfred Infanger ${ }^{\mathrm{b}}$ Christoph Eilles ${ }^{\mathrm{a}}$ Daniela Grimm ${ }^{\mathrm{b}, \mathrm{d}}$ \\ ${ }^{a}$ Department of Nuclear Medicine, University of Regensburg, Regensburg, Germany; ${ }^{b} C l i n i c$ for Plastic, \\ Aesthetic and Hand Surgery, Otto-von-Guericke-University Magdeburg, Magdeburg, Germany; \\ 'Department of Radiooncology, University of Regensburg, Regensburg, Germany; 'Institute of \\ Biomedicine, Pharmacology, Aarhus University, Aarhus, Denmark; eMedical Research Laboratories, \\ Department of Clinical Medicine, Faculty of Health Sciences, Aarhus University, Denmark
}

\section{Key Words}

Thyroid cancer $\cdot$ Sunitinib • Cytokines $•$ Radiation $•$ VEGF $•$ Gene expression

\begin{abstract}
Background/Aims: Thyroid cancer accounts for about 1\% of all cancer cases. Multikinase inhibitors like sunitinib (S) have a promising potential in thyroid cancer therapy. Therefore, the principal aim of this study was to investigate the impact of sunitinib on the secretion of cytokines of follicular thyroid cancer cells. Method: The effects of irradiation (R), S, and their combination $(R+S)$ on cytokine secretion by the human thyroid cancer cell lines $M L-1$ and CGTH W-1 were evaluated after two (d2) and four days (d4) of treatment. Results: MultiAnalyte Profiling of cytokine release showed a decrease after $\mathrm{S}$ treatment (CGTH W-1: IFN- $\gamma$, IL-4, IL-8 d2, MIP-1a, MMP-2, TNF- $\alpha$ and TNF- $\beta$; ML-1: IFN- $\gamma$, IL-4, IL-6, IL-7, IL-8; MIP-1 $\alpha$, MMP-2, MCP-1, TNF- $\alpha$ and TNF- $\beta$ ). R elevated significantly the release of cytokines (exception ML-1: MCP-1, MMP-2; CGTH W-1: IL-4, TNF- $\beta$ ). In contrast, $R+S$ treatment resulted in a reduction of IFN- $\gamma$, IL-4, and MMP-2 in both cell lines. IL-6, IL-8 and MCP-1 proteins in the supernatant correlated with the data obtained by quantitative RT-PCR. VEGFD mRNAs were significantly elevated by $\mathrm{R}+\mathrm{S}$. Conclusion: $\mathrm{A}$ target-based therapy with $\mathrm{R}+\mathrm{S}$ changed VEGFD, $I L-6$ and $I L-8$ in follicular thyroid cancer cells. These in vitro-experiments suggest IL-6, IL-8, VEGFD and TNF- $\alpha$ as interesting biomarkers to be investigated in vivo. Different reactions of the cell lines under equal treatment might be due to their different origin and characteristics.
\end{abstract}

Copyright $@ 2013$ S. Karger AG, Basel

\section{Introduction}

With $1 \%$ of all malignancies, thyroid cancer is the most common malignant endocrine tumor [1]. It is a very heterogeneous group of tumors. Papillary thyroid cancer (PTC) and follicular thyroid cancer (FTC) can be classified as differentiated thyroid cancer (DTC) [2]. When appropriate treatment is given, the 10-year survival rate of minimally invasive 
FTC is $80-90 \%$ [3]. According to the guidelines of the American Thyroid Association and European Association of Nuclear Medicine, the treatment of DTC includes total or near-total thyroidectomy followed by radioiodine ablation. A high risk of local recurrence, postoperative residual tumor, and a missing or insufficient uptake of radioiodine (i.e., poorly differentiated thyroid carcinoma, increasing dedifferentiation) are indications for irradiation. Cancer progression after radioiodine therapy caused by an increasing dedifferentiation in polytope metastasized tumors requires other systemic therapies, because the 10-year survival rate is $<15 \%$ [4]. Commonly used cytostatic chemotherapeutic substances show only limited and transient response rates of $0-22 \%$ and are associated with significant toxicity [5]. The establishment of new chemotherapeutic treatment options is, therefore, urgently needed.

Oral tyrosine kinase inhibitors (TKI), such as sunitinib, seem to be promising candidates since they successfully suppress both neoangiogenesis and tumor proliferation [6]. Sunitinib mediates its effect primarily by binding and antagonizing the vascular endothelial growth factor receptor (VEGFR) and platelet-derived growth factor receptor (PDGFR) kinases, as well as c-KIT, RET, and the fetal liver tyrosine kinase (FLT3) [6, 7]. The FDA and EMEA already approved sunitinib for the treatment of several kinds of tumors [8]. In addition, sunitinib proved to be a potential therapeutic approach in a number of clinical trials for patients with radioiodine-refractory and medullary thyroid carcinoma (MTC) [9]. After sunitinibtreatment of 35 patients suffering from radioiodine-refractory DTC and MTC in a clinical trial (phase II), a complete response was observed in $3 \%$ of the patients, a partial response in $28 \%$, and tumor stabilization in $48 \%$ [10]. In the therapy of gastrointestinal tumors and metastatic renal cancer with sunitinib, the effects on the thyroid could be evaluated. After treatment over 37 weeks, $36 \%$ of the patients showed primary hypothyroidism. The risk of hypothyroidism rose with increasing duration of therapy [11]. In a case report of a 60-yearold woman whose metastatic kidney cancer was treated with sunitinib, atrophia of the thyroid with hypothyroidism and reduced vascularity were observed. In periods without treatment, a recovery of the thyroid volume with increased vascularity was detectable. This observation suggests that thyroid function and volume depend on the vascularity. Thus, a reduced blood flow by capillary regression and constriction would be a possible explanation for the observed hypothyroidism [12]. Moreover, treatment with sunitinib led to noncompetitive inhibition of thyroid hormone transporters. It could be shown that TKI exposure of Madin-Darby-canine kidney cells dose-dependently inhibited human monocarboxylate transporter 8 (MCT8)-dependent T3- and T4-uptake. A partial inhibition of MCT8 would offer an explanation for the reversibility of reduced thyroid function. The inhibition of thyroid hormone transport leads to changes in circulating thyroid hormone levels which could be related to fatigue, which is known to be a common side effect of TKI therapy [13]. Using a mouse model it could be shown that sunitinib enhances radiation-induced cytotoxic effects in endothelial cells [14]. The combination of irradiation and sunitinib significantly reduces tumor vascularization compared to both monotherapies. This observation suggests that a combined therapy with TKI and irradiation might be a promising treatment paradigm.

Cytokines are suggested to play an important role in many processes associated with cancer such as tumor cell proliferation, apoptosis, tumor invasion, angiogenesis, and metastatic tumor cell dissemination [15]. In addition, cytokines, such as transforming growth factor (TGF)- $\beta$, interleukin (IL)-1, IL-6 and tumor necrosis factor (TNF)- $\alpha$ appear to be promising molecular markers of radiation-induced effects [16]. Apoptosis and necrosis are detectable after irradiation of cells, whereas the damage without cell death stimulates signaling pathways of inflammation and angiogenesis [16]. Using a mouse model it was shown that pulmonary irradiation is accompanied by an early and persistent expression of cytokines [17]. Comparing the temporal course of cytokine production with histological changes, the authors suggested that an early and enduring production of cytokines leads to radiation-induced pulmonary fibrosis. After in vitro and in vivo treatment of MTC with sunitinib, cytokines were also identified as potential biomarkers for response to treatment [18]. After therapy with sunitinib, a significant decrease of tumor growth and angiogenesis was observed in xenografted mice associated with a significantly decreased expression and 
serum levels of IL-8. Furthermore, it could be demonstrated that patients suffering from metastatic MTC showed increased serum levels of IL- 8 and TGF- $\beta$ compared to the healthy control group. Hence, IL-8 appears interesting as a therapeutic target and as a clinical biomarker.

Therefore, the principal aim of this study was to investigate potential biomarkers after irradiation, treatment with sunitinib and the combination of both therapeutic approaches in follicular thyroid cancer cells in vitro. Since overexpression of IL- 6 and IL-8 has been associated with an inferior outcome in patients with rectal and colon cancer $[19,20]$, it is of major interest to investigate these cytokines in follicular thyroid cancer cells and to examine whether sunitinib can influence their secretion in vitro.

\section{Materials and Methods}

\section{Cell culturing of $M L-1$ and CGTH $W-1$}

The human follicular thyroid carcinoma cell lines ML-1 [21] and CGTH W-1 [22] were cultured in RPMI-1640 medium containing $100 \mu \mathrm{M}$ sodium pyruvate and $2 \mathrm{mM}$ L-glutamine, supplemented with $100 \mathrm{U} / \mathrm{mL}$ penicillin and $100 \mu \mathrm{g} / \mathrm{mL}$ streptomycin (both Invitrogen, Eggenstein, Germany) and 10\% FCS (Biochrom, Berlin, Germany) under standard conditions as previously described [23]. The medium for the chemotherapeutic treatment contains sunitinib in a concentration of $1 \mu \mathrm{mol} / \mathrm{L}$ as described by Piscazzi et al. [24].

After reaching a subconfluency of $90 \%$, culture flasks (Sarstedt, Numbrecht, Germany) were randomised to the following study groups (each $n=5$ ): control cells $(C)$, cells for sunitinib treatment $(S)$, cells for irradiation (R), and cells for a combined treatment with sunitinib and irradiation ( $R+S)$. All cells/ supernatants were investigated at days 2 and 4 after irradiation/start of treatment with sunitinib. Control cells were investigated at the same time points.

\section{Irradiation}

For irradiation, X-rays generated at a dose rate of $3 \mathrm{~Gy} / \mathrm{min}$ by a 6-MV linear accelerator (Primus, Siemens, Germany) were used as described previously $[23,25,26]$. The cells were cultured in T175 culture flasks. The focus-isocenter distance was $100 \mathrm{~cm}$. The isocenter was in the centre of the cell medium. A plate of Perspex was above (thickness, $2 \mathrm{~cm}$ ) and below (thickness, $2 \mathrm{~cm}$ ) the tissue culture flasks to compensate for the buildup effect. The irradiation was delivered at room temperature by an anterior portal.

An equivalent of $30 \times 30 \mathrm{~cm}$ was used for calculation of treatment time after dosimetric evaluations were performed to guarantee a homogenous dose distribution. We chose a sublethal dose of 30 Gy, comparable to those applied in radioiodine therapy, to achieve a maximal amount of apoptosis or necrosis [27].

Cytokine measurements by Multi-Analyte Profiling technology

All supernatants were stored at $-80{ }^{\circ} \mathrm{C}$ until tested. Quantification of secreted soluble factors was carried out by Myriad RBM (Austin, Texas, USA) using the Human CytokineMAP A Kit (see Tables 1+2) for Multi-Analyte Profiling [28-30]. The platform uses multi-level internal controls and uses a 4 or 5 parameter algorithm for curve fitting based on eight point standard curves for each analyte. Prior to multiplexing the platform has been validated individually for each analyte in terms of detection limit, precision, crossreactivity, linearity, spike-recovery, dynamic range, matrix interference, freeze-thaw stability, and shortterm sample stability.

\section{Determination of $V E G F_{165}$}

VEGF levels were determined using an in-house, time-resolved immunofluorometric assay based on VEGF antibodies and recombinant VEGF from R\&D Systems (Abingdon, United Kingdom) (unpublished). Cell culture supernatants were diluted 1:2 and analyzed in duplicate. Intra-assay coefficients of variation of standards, controls, unknown samples, and nonspecific background controls averaged $<5 \%$. VEGF concentrations were determined using a 4-parameter standard curve fit implemented in WorkOut 2.5 Data Analysis software (Perkin Elmer Inc., Waltham, MA). Mean values were calculated and used for statistical analyses. 

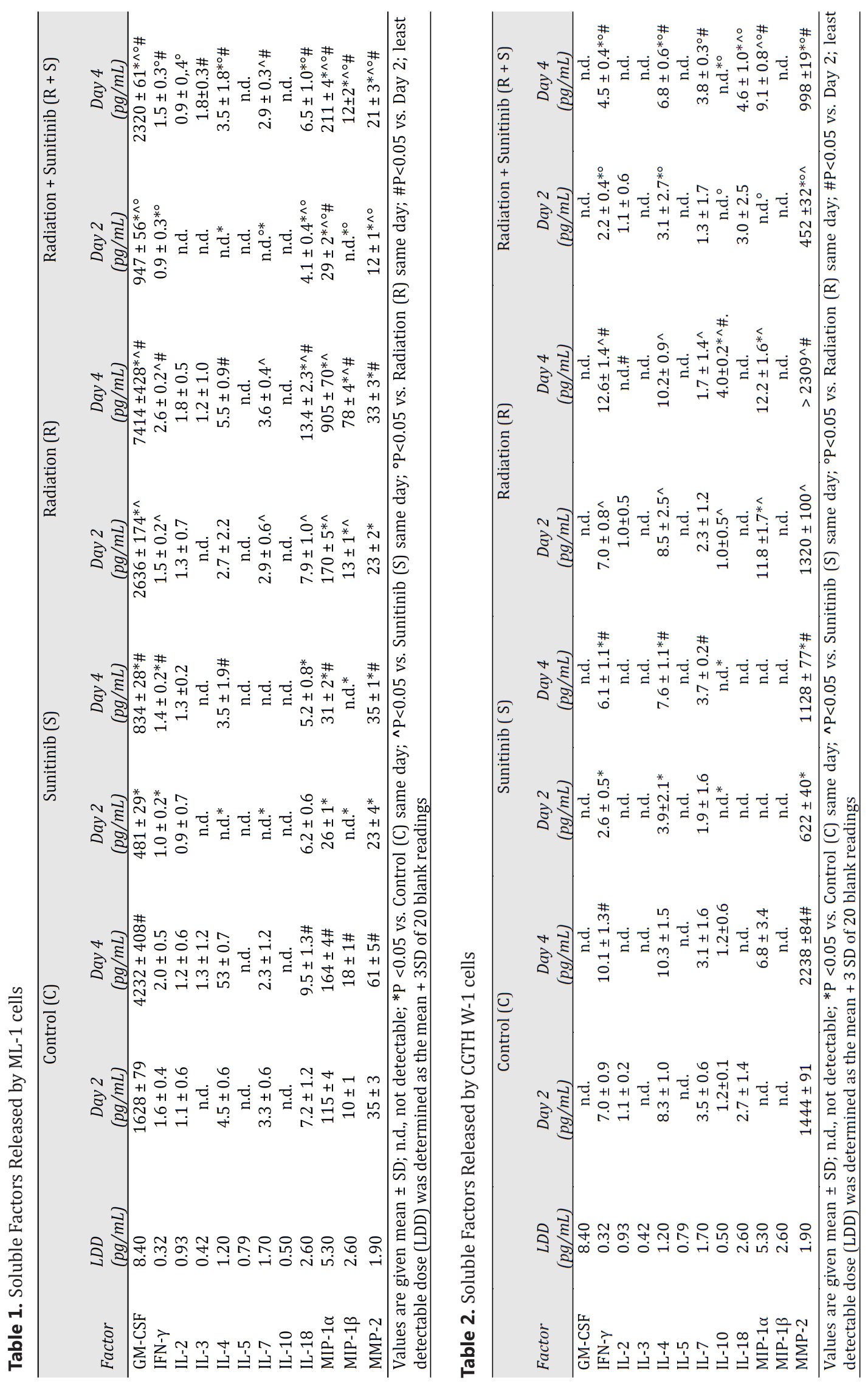
Grosse et al.: Sunitinib and Thyroid Cancer Cells

RNA isolation and quantitative realtime PCR

All cell culture flasks of each group were used for RNA extraction. RNA concentrations and quality were determined following routine protocols. Quantitative real-time PCR was carried out to determine the expression levels of the genes of interest (see Table 3). To design appropriate primers with $\mathrm{T}_{\mathrm{m}} \sim 60$ ${ }^{\circ} \mathrm{C}$, Primer Express software (Applied Biosystems, Darmstadt, Germany) was used. All primers were synthesized by TIB Molbiol (Berlin, Germany). Details of the methods were previously published [31-33].

\section{Statistical Evaluation}

SPSS version 16.0 (SPSS Inc., Chicago, IL, USA) was used for statistical analysis. All data are expressed as mean values \pm standard deviation (SD). Statistical Whitney U test where applicable. Differences were considered significant at the level of $p<0.05$. are given in 5'-3' direction
Table 3. Primers used for quantitative real-time PCR. All sequences

\begin{tabular}{lll}
\hline Gene & Primer Name & Sequence \\
\hline 18S rRNA & 18S-F & GGAGCCTGCGGCTTAATT \\
& 18S-R & CAACTAAGAACGGCCATGCA \\
FLK1 & FLK1-F & TCTTCTGGCTACTTCTTGTCATCATC \\
& FLK1-R & GATGGACAAGTAGCCTGTCTTCAGT \\
FLT1 & FLT1-F & CCCTCGCCGGAAGTTGTAT \\
& FLT1-R & GATAATTAACGAGTAGCCACGAGTCAA \\
IL6 & IL6-F & CGGGAACGAAAGAGAAGCTCTA \\
& IL6-R & GAGCAGCCCAGGGAGAA \\
IL8 & IL8-F & TGGCAGCCTTCCTGATTTCT \\
& IL8-R & GGGTGGAAAGTTTGGAGTATG \\
MCP1 & MCP1-F & GCTATAGAAGAATCACCAGCAGCAA \\
& MCP1-R & TGGAATCCTGAACCCACTTCTG \\
TNFA & TNFA-F & TGATCGGTCCAACAAGGA \\
& TNFA-R & TGGGCTACGGGCTTGTCA \\
TNFB & TNFB-F & CCCACAGCACCCTCAAACC \\
& TNFB-R & GAAGGCACGGTCCGTGTT \\
VEGFA & VEGFA-F & GCGCTGATAGACATCCATGAAC \\
& VEGFA-R & CTACCTCCACCATGCCAAGTG \\
VEGFD & VEGFD-F & TGCAGGAGGAAATCCACTTG \\
& VEGFD-R & CTCGCAACGATCTTCGTCAA \\
\hline
\end{tabular}

al analysis was performed using one-way ANOVA or the MannResults

Impact of radiation and/or sunitinib on Vascular Endothelial Growth Factors

$M L-1$ cell line. Expression of the VEGFA gene remained unchanged in sunitinib (S)treated cells at day 2 and day 4 compared with control cells. Irradiated cells in combination with $\mathrm{S}(\mathrm{R}+\mathrm{S})$ exhibited a significant upregulation of VEGFA at both examined time points in comparison to control and S-treated cells (Fig. 1A).

Expression of VEGFD (Fig. 1C) was significantly elevated at days 2 and 4 after S application compared with controls (C). Radiation induced a slight, but significant, increase of VEGFD compared with control cells. The effect of $S$ was much more pronounced than the influence of radiation on VEGFD expression. The $\mathrm{R}+\mathrm{S}$ treatment produced a further elevation of VEGFD expression at both examination days, but the effect was still lower than in the $\mathrm{S}$ group (Fig. 1C).

$\mathrm{VEGF}_{165}$ was elevated at day 4 in the $\mathrm{S}, \mathrm{R}$, and $\mathrm{R}+\mathrm{S}$ groups compared to the controls. The amount of VEGF 165 protein was low at day 2 in control cells, but completely suppressed in all treatment groups at day 2 (Fig. 1E). The R+S treatment reduced $\mathrm{VEGF}_{165}$ secretion at day 4 compared with the $\mathrm{S}$ and $\mathrm{R}$ treatments.

FLK1 mRNA was only elevated at day 2 in radiated and S-treated cells, but it was unchanged in all other groups (Fig. 1G), with the exception of day 4 in irradiated cells.

CGTH $W$-1 cell line. VEGFA mRNA levels were elevated by radiation, while $S$ monotherapy had no effect. The $\mathrm{R}+\mathrm{S}$ combined therapy reduced VEGFA expression significantly compared to $\mathrm{R}$ alone, but was unchanged compared with controls (Fig. 1B). In the case of VEGFD, $\mathrm{R}+\mathrm{S}$ significantly increased its mRNA levels (Fig. 1D).

VEGF $_{165}$ was released in equal amounts on days 2 and 4 in the supernatants of CGTH W-1 cells; this secretion was suppressed by $S$ and R+S (Fig. 1F).

The FLK1 gene was downregulated at day 4 in control cells compared to day 2. S inhibited the expression of FLK1, while $\mathrm{R}$ and $\mathrm{R}+\mathrm{S}$ upregulated FLK1 expression. The latter was slightly reduced again in comparison to the radiation therapy alone, and a significant downregulation of the gene was also found between days 2 and 4 in $R$ and $R+S$-treated cells (Fig. 1H). 


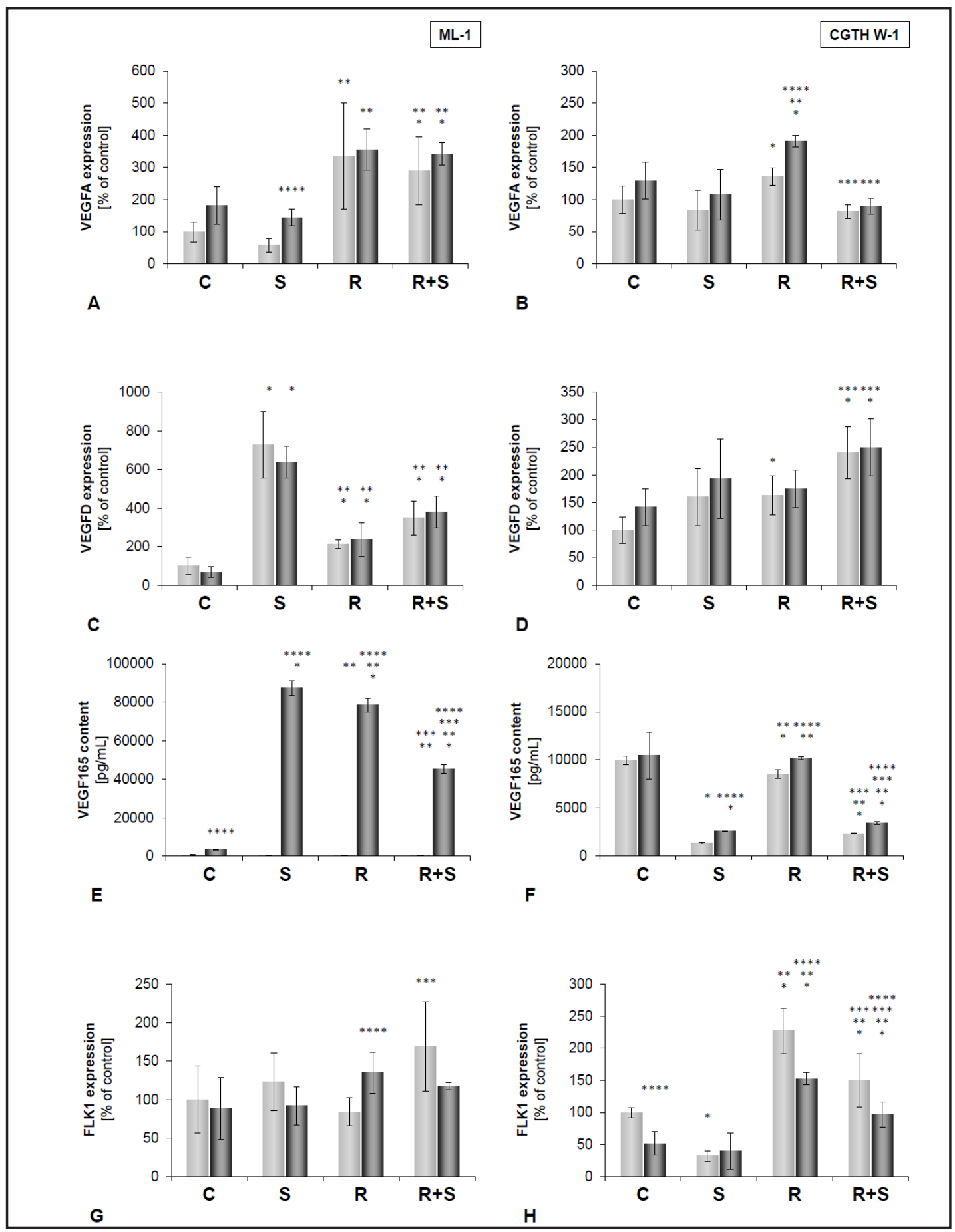

Fig. 1. Quantitative real-time PCR was used to determine the gene expression of VEGFA (A, B), VEGFD (C, D) and FLK1 $(\mathrm{G}, \mathrm{H})$. Furthermore the release of VEGF165 (E, F) into the cell supernatant was measured. The results are shown for the cell lines ML-1 (A, C, E, G) and CGTH W-1 (B, D, F, H). Control cells (C) were grown without treatment. For the other groups, either sunitinib $(S)$, radiation $(R)$ or the combination of sunitinib and radiation $(\mathrm{R}+\mathrm{S})$ were applied to the cells. Harvesting took place after two days (light grey) and four days (dark grey). ${ }^{\star} P<0.05$ vs. control, ${ }^{\star *} P<0.05$ vs. sunitinib, ${ }^{* *} P<0.05$ vs. radiation, ${ }^{* * * *} P<0.05$ vs. $2 \mathrm{~d}$.

The influence of sunitinib and/or radiation on cytokines

To obtain an overview of the soluble factors secreted by the tumour cells in the supernatant, MAP was performed to measure the following cytokines: GM-CSF, IFN- $\gamma$, 


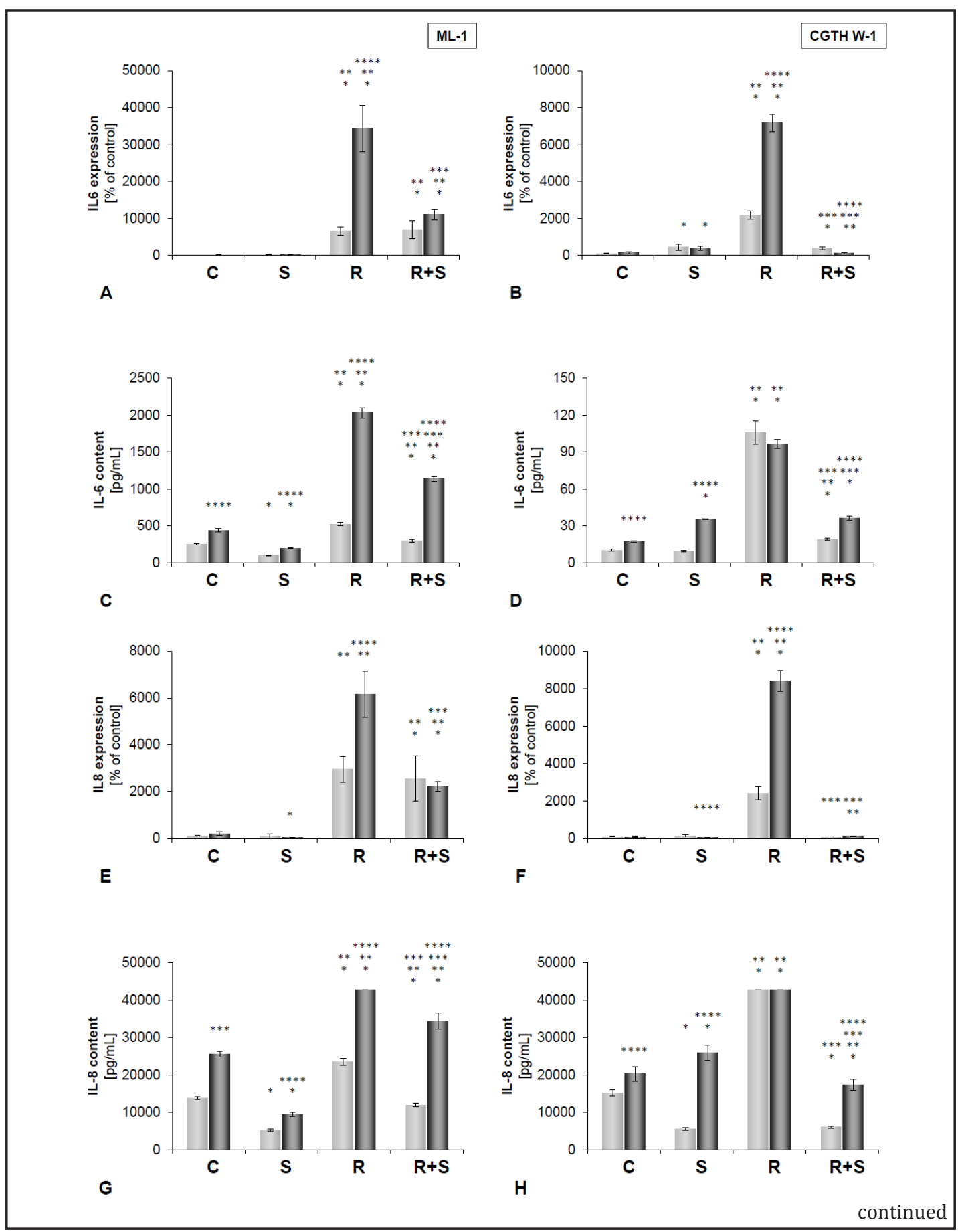

Fig. 2. Quantitative real-time PCR was used to determine the gene expression of IL-6 (A, B), IL-8 (E, F) and MCP-1 (I, J). "Multi-Analyte Profiling" was used to determine IL-6 (C, D), IL-8 (G, H) and MCP-1 (K, L) release by ML-1 (A, C, E, G, I, K) and CGTH W-1 (B, D, F, H, J, L) cells. Control cells (C) were grown without treatment. For the other groups, either sunitinib $(S)$, radiation $(R)$ or the combination of sunitinib and radiation $(R+S)$ were applied to the cells. Harvesting took place after two days (light grey) and four days (dark grey). ${ }^{\star} P<0.05$ vs. control, ${ }^{* *} P<0.05$ vs. sunitinib, ${ }^{* * *} P<0.05$ vs. radiation, ${ }^{* * * *} P<0.05$ vs. 2 d.

IL-2, IL-3, IL-4, IL-5, IL-6, IL-7, IL-8, IL-10, IL-18, MIP-1 $\alpha$, MIP-1 $\beta$, MMP-2, MCP-1, TNF- $\alpha$ and TNF- $\beta$. These results are demonstrated in Tables 1 and 2 as well as in Figures 2 and 3. 


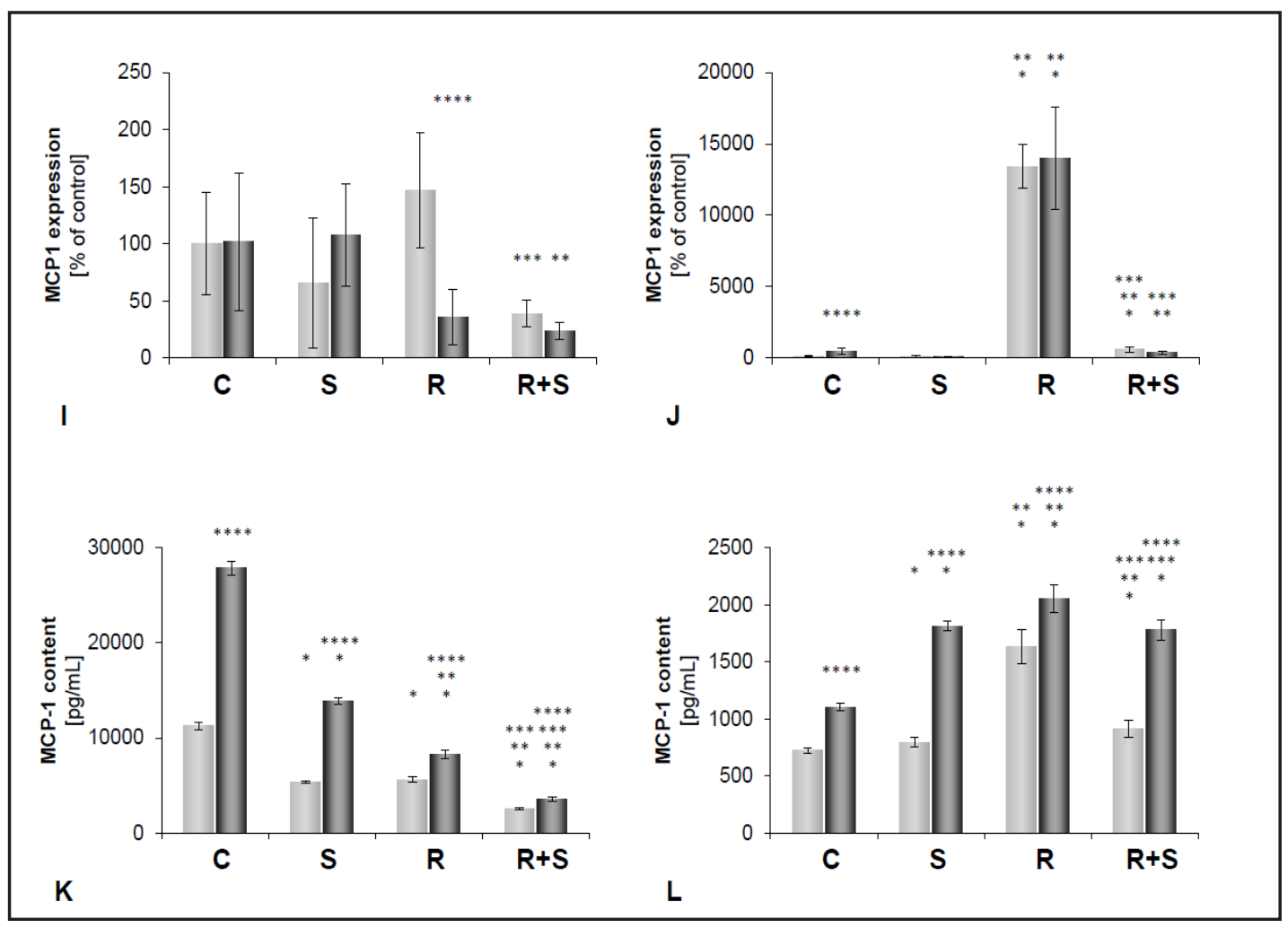

ML-1 cell line. The concentrations of IL-5 and IL-10 were below the least detectable dose (LDD). IL-3, IL-4 and IL-7 concentrations were partly below the LDD. The strongest effects were found for IL-6, IL-8, MCP-1, TNF- $\alpha$, TNF- $\beta$, GM-CSF, IFN- $\gamma$, MIP- $1 \alpha$ and MIP-1 $\beta$ (Table 1 ).

In general, the cytokine concentrations followed a similar pattern. In most cases, the analytes increased between days 2 and 4, independently of the treatment. Moreover, a monotherapy with $\mathrm{S}$ showed in all investigated cytokines a reduced secretion of the proteins. Upon radiation, we found an elevation of the cytokines in ML-1 cells with the exception of IL-3, IL-4, MCP-1 and MMP-2 (Table 1). Levels of IL-8 were elevated above the detection limit (Fig. 2G). The combination therapy showed reduced cytokine production at day 2 in comparison to the radiation group (Table 1 ).

CGTH W-1 cell line. Cytokines GM-CSF, IL-3, IL-5, and MIP-1 $\beta$ were below the detection limit. This was partially also the case for IL-2, IL-10, IL-18, MIP- $1 \alpha$, TNF- $\alpha$ and TNF- $\beta$ (Table 2).

CGTH W-1 exhibited an increased release of the cytokines between days 2 and 4, independently of treatment with the exception of IL-6, IL-7 and TNF- $\alpha$. S treatment resulted in a reduced release of IFN- $\gamma$, IL-4, IL-7, IL-8, and MMP-2 at day 2. Radiation induced MIP-1 $\alpha$, TNF- $\alpha$ und TNF- $\beta$. IFN- $\gamma$ and IL-4 showed no differences after radiation. IL- 7 was reduced at both time points. MMP-2 was enhanced at day 4 after radiation. Combination therapy resulted in levels below the LDD for IL-10, MIP-1 $\alpha$ and TNF- $\alpha$ at day 2 (Table 2, Fig. 3).

Impact of radiation and sunitinib on $I L-6, I L-8$ and $M C P-1$

ML-1 cell line. IL6 and IL8 mRNAs were suppressed in control and S-treated cells. Radiation elevated IL6 and IL8 expression at day 2 and strongly upregulated it at day 4 compared with $\mathrm{C}$ and $\mathrm{S}$ treatments. This effect was attenuated in $\mathrm{R}+\mathrm{S}$-treated cells at day 4 (Figs. 2A and E). In parallel, we detected an elevated release of IL-6 protein in the supernatant by radiation at day 2 , which was more pronounced at day 4 post-radiation. Comparable to the gene expression, the release of IL- 6 protein was reduced in $\mathrm{R}+\mathrm{S}$ at days 2 and 4 compared to R (Fig. 2C). 


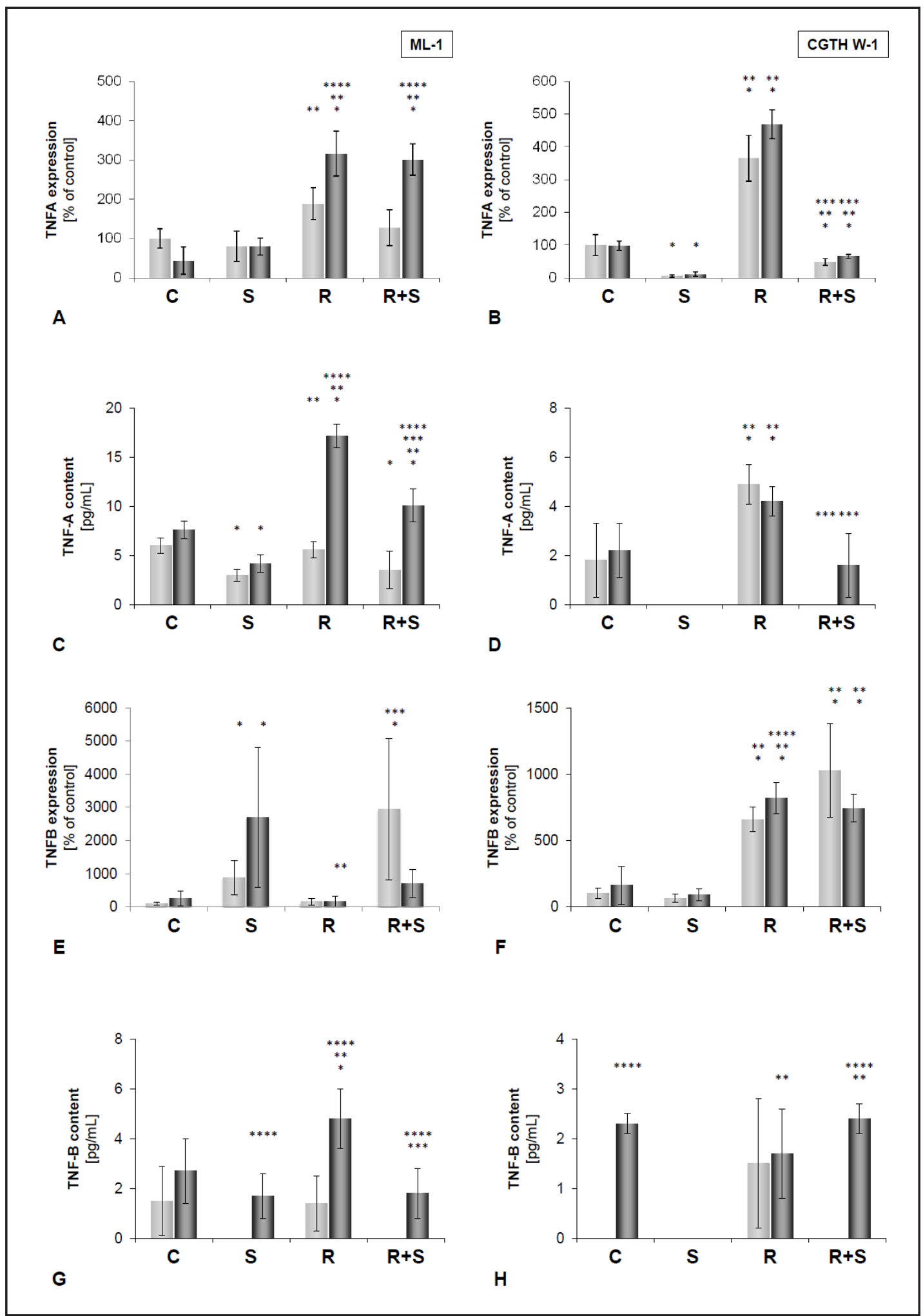

Fig. 3. Gene expression of TNFA (A, B) and TNFB (E, F) in ML-1 (A, E) and CGTH W-1 (B, F) cells. TNF- $\alpha$ secretion measured by MAP is shown in C, D and TNF- $\beta$ secretion in $G, H$. Control cells $(C)$ were grown without treatment. For the other groups, either sunitinib (S), radiation $(\mathrm{R})$ or the combination of sunitinib and radiation $(\mathrm{R}+\mathrm{S})$ were applied to the cells. Harvesting took place after two days (light grey) and four days (dark grey). ${ }^{\star} P<0.05$ vs. control, ${ }^{* *} P<0.05$ vs. sunitinib, ${ }^{* * *} P<0.05$ vs. radiation, ${ }^{* * * *} P<0.05$ vs. $2 \mathrm{~d}$. 
In addition, control cells released a high amount of IL-8 protein in the supernatant. This release was significantly inhibited by S. R induced a rise in IL-8 at day 2, which was further enhanced at day 4 . Furthermore, an enhanced release was measured in $\mathrm{R}+\mathrm{S}$ cells at day 4 (Fig. 2G).

Expression of MCP1 was not significantly altered in $\mathrm{S}$ and $\mathrm{R}$ compared with controls. In the $\mathrm{R}+\mathrm{S}$ group, $M C P 1$ mRNA was downregulated at both days (Fig. 2I). Release of MCP1 protein into the supernatant was significantly elevated in $\mathrm{C}, \mathrm{S}$ and $\mathrm{R}$ at day 4 compared with day 2 . S attenuated this release in the $S$ and the $R+S$ groups at both days. In addition, $\mathrm{R}$ induced a reduction at both days compared to the $\mathrm{C}$ group (Fig. $2 \mathrm{~K}$ ).

CGTH W-1 cell line. IL6 and IL8 mRNA expression were suppressed in control cells, and IL6 was elevated in S-treated cells; both cytokines were elevated at day 2 and further significantly enhanced at day 4 in R cells. The combination therapy decreased the expression of $I L 6$ and $I L 8$ mRNAs at both days (Figs. 2B, 2F).

Moreover, we investigated the secretion rate of IL-6 in the supernatant. Control cells showed a low secretion of the cytokine (below $15 \mathrm{pg} / \mathrm{mL}$ ), but this rate was elevated by $\mathrm{S}$ at day 4. A strong increase of IL-6 (10-fold) was detected after radiation at both time-points, which was attenuated again by combined therapy (R+S group) (Fig. 2D). IL-8 was released in high amounts in CGTH W-1 control cells. Initially, sunitinib decreased the amount of IL-8 in the supernatant, but at day 4 the secretion rate was enhanced again to a higher IL-8 level than at day 2. Radiation induced a strong increase of the cytokine, which was attenuated by the combined therapy (Fig. $2 \mathrm{H}$ ).

The mRNA expression of MCP1 was suppressed in the $\mathrm{C}$ and $\mathrm{S}$ group. Radiation therapy resulted in a strong elevation in $M C P 1$ mRNA at both investigation days. In contrast, the combined therapy suppressed the mRNA level of this cytokine (Fig. 2J). A completely different behavior was observed for the secreted soluble MCP1 protein. Sunitinib significantly elevated the amount of secreted MCP1 in the supernatant at day 4. Combined radiation and sunitinib application exerted no synergistic effect. In contrast, the level of MCP1 was less at day 2.

Impact of sunitinib and/or radiation on TNF-alpha and TNF-beta

Expression of TNFA was low in both cell lines and even suppressed by $\mathrm{S}$ in the CGTH W-1 cell line. R resulted in an increase of TNFA mRNA at day 2 and a further elevation at day 4 in both cell lines. The combined therapy reduced the gene expression at day 2 in ML-1 and CGTH W-1 cells. At day 4 we found a different result in both cell lines. In CGTH W-1 cells TNFA mRNA remained reduced, whereas in ML-1 cells the mRNA levels were elevated again (Figs. 3A, 3B). Both cell lines secreted TNF- $\alpha$ into the supernatant. S significantly reduced the secretion rate of both cell lines. In both cell lines, $\mathrm{R}$ increased the amount of soluble TNF- $\alpha$ again, but this was more pronounced in ML-1 cells. $\mathrm{R}+\mathrm{S}$ reduced this amount again (Figs. 3C, 3D).

The TNFB mRNA was very low in control cells of both cell lines, but it was elevated in ML-1 cells by S. Radiation had no effects in ML-1 cells, but induced an increase in CGTH $\mathrm{W}-1$ cells. The combined therapy induced an elevation of the TNFB gene expression in both cell lines at day 2 , which was reduced again at day 4 (Figs. 3C, 3D). TNF- $\beta$ was secreted at low levels in ML-1 cells at day 2 and 4 and in CGTH W-1 cells at day 4. S suppressed this secretion at day 2 completely in both cell lines. At day 4, the secretion increased in ML-1 cells but not in CGTH W-1 cells. $\mathrm{R}+\mathrm{S}$ induced a slight secretion in both cell lines comparable to the baseline secretion of the cells at day 4 (Figs. 3G, 3H).

\section{Discussion}

The principal aim of this paper was to investigate the influence of irradiation and sunitinib in combination or as a single application on the release of cytokines by the human follicular thyroid cancer cell lines ML-1 and CGTH W-1. The ML-1 cell line was established 
from a poorly differentiated follicular thyroid carcinoma [21], whereas the CGTH W-1 cell line originated from a sternal metastasis [22]. The CGTH W-1 cell line was extensively studied by our group [34-37]. Moreover, Chang et al. [38] compared the IL-6 and TGF- $\beta 1$ secretion of CGTH W-1 cells with their established Thena cells. The CGTH W-1 cell line is tumorigenous in nude mice and was molecular cytogenetically characterized by Foukakis et al. [39]. Other teams investigated the antitumor effects of arsenic trioxide on CGTH W-1 cells [40] or used the cell line for treatment with estrogen alone or estrogen and anti-estrogens [41]. Their data establish estrogen as being a key regulator of VEGF secretion/expression in thyroid cells which enhances the process of angiogenesis in thyroid cancer.

VEGF inhibitors are innovative medications inhibiting a tumors supply of nutrients and, thus, lead to the death of tumor cells. This concept of cancer therapy is called neoangiogenesis inhibition [42, 43]. This targeted therapy inhibits the metabolism and growth signals of cancer cells. Sunitinib, an oral multityrosine kinase inhibitor, was used as a therapeutic agent because it showed beneficial effects in clinical phase II studies in patients with radioiodine refractory as well as medullary thyroid carcinomas [9]. A continuous application of sunitinib was effective in these patients [10]. Further studies supported these findings [44]. Sunitinib is a multitarget inhibitor with activity against the VEGF-receptor-2, PDGF receptor b, stem cell factor receptor (C-kit) and FLT3 tyrosine kinase signaling pathways [7]. Thus, blockade of several kinases successfully suppressed tumor cell proliferation and neoangiogenesis in tumor cells, endothelial cells and pericytes [45]. Moreover, Schueneman et al. [14] showed that sunitinib increased the radiation-induced cytotoxicity on endothelial cells, which was partly the result of an elevated apoptosis rate. As described by Piscazzi et al. [24], sunitinib seems to target the cytosolic MAPK kinase (MEK)/ERK and stress-activated protein kinase/ c-Jun N-terminal kinase pathways in RET/PTC cell lines. One may suggest that blocking these pathways is part of the mechanism by which sunitinib exerts its direct antiproliferative activity. As the authors show, sunitinib is able to induce a similar inhibition of cell proliferation in TPC-1, ML-1, and WRO cells that is not dependent on a selective induction of apoptosis. This inhibition correlated with the accumulation of cells in the G0-G1 phase of cell cycle and the parallel inhibition of S phase. All sunitinib-sensitive thyroid cancer cell lines exhibited wild-type KRAS and BRAF genotypes.

\section{Influence of irradiation and sunitinib on VEGF and VEGF receptors}

To evaluate the treatment effects, the cells were collected at day 2 and 4 post-radiation and subsequently investigated by quantitative real-time PCR to measure the gene expression of VEGFA, VEGFD and FLK1. Moreover, we measured the release of VEGF 165 by both cell lines. Both cancer cell lines expressed VEGFA, VEGFD and FLK1 mRNAs. VEGF-A expression is correlated with thyroid cancer growth, recurrence and metastasis. It is possible that the substantial constitutive secretion of VEGF-A by ML-1 cells contributed to the recurrence, metastatic and invasive potential of the original tumor [21].

Sunitinib in combination with radiation elevated VEGFA mRNA levels compared with control cells, but reduced the amount of VEGFA mRNA in CGTH W-1 cells compared to R. In contrast, FLK1 was only slightly expressed in ML-1 cells, but at day 2 the post-radiation and sunitinib applications resulted in a significant increase, which was not detectable at day 4. A similar result was found in CGTH W-1 cells in the R+S group. The basal levels of VEGF ${ }_{165}$ secretion were distinctly lower in ML-1 cells. Earlier investigations have demonstrated that the ML-1 cell line is VEGFA-positive [46]. Sunitinib inhibited the VEGF ${ }_{165}$ secretion after 2 days completely followed by increased secretion after 4 days. This was lower in the $\mathrm{R}+\mathrm{S}$ group. The increased secretion of VEGF ${ }_{165}$ after treatment with $\mathrm{S}, \mathrm{R}$ or $\mathrm{R}+\mathrm{S}$ may be physiologically important for the tumorigenic potential of ML-1 cells by stimulating angiogenesis and/or lymphangiogenesis. CGTH W-1 showed a different reaction. Sunitinib as monotherapy or in combination with radiation reduced the secretion rate.

A very interesting result was that VEGFD was clearly upregulated in irradiated as well as sunitinib-treated cells. VEGFD promotes lymphangiogenesis, which further supports metastasis in lymphatic vessels. Nersita et al. [47] had demonstrated a low VEGFD serum 
level in patients with metastasized, differentiated thyroid carcinoma, whereas high VEGFD level in patients were correlated with a positive outcome. One may suggest that an increased level of VEGFD after radiation and/or sunitinib is correlated with beneficial effects in patients. On the other hand, high serum VEGFD levels have been shown to be correlated with lymph node metastases in patients suffering from papillary thyroid carcinoma (PTC) [48]. Furthermore, Yasuoka et al. observed, that VEGFD expression in papillary thyroid tumors as well as in the K1 PTC cell line significantly coincided with neuropilin-2 expression and the occurrence of lymp node metastases [49]. In a phase II study with sunitinib-malat application to women with metastasized breast cancer and pretreatment with anthracylins and taxanes, an increase of plasma-VEGF, a decrease of soluble VEGFR and KIT were detectable [50]. Moreover, VEGFR1 (FLT1) mRNA levels were below the detection limit of the quantitative RT-PCR. Piscazzi et al. have published this result for the ML-1 cell line already in their recent manuscript [24]. In parallel, these authors [24] also demonstrated a lower level of VEGF2 in ML-1 cells. An increased intracellular signal transduction via VEGFR2, MAP kinases and Akt is an important characteristic of thyroid carcinomas and endothelial cells, and successful targeted inhibition of VEGFR2 in endothelial cells and potentially in thyroid cancer cells has been demonstrated [51].

\section{Effects of irradiation and sunitinib application on the expression of cytokines}

$I L-6$ and $I L-8$ mRNAs were both strongly elevated in irradiated samples. Combined treatment of radiation and sunitinib induced a downregulation of both $I L-6$ and $I L-8$. Cytokines play a key role in the development and expression of epithelial tumors. Normal thyrocytes secrete both cytokines in the supernatant [52]. Reduced IL-6-expression was found in anaplastic thyroid carcinomas [53]. These results are in accordance with our previous data: high IL-6 and IL-8 levels induced an increased three-dimensional growth [54]. Therefore, the reduction of IL-6 and IL-8 with sunitinib therapy mainly in combination with radiation suggests beneficial effects of the substance in follicular thyroid carcinomas. A recent publication from Porta et al. demonstrated that a high IL-6 content is associated with an enhanced tumor progression in advanced renal cell carcinomas [55]. Zhu et al. showed a modulation of serumlevels of IL-6, IL-8, TNF- $\alpha$ after inhibition of tyrosine kinases with sunitinib in patients with hepatocellular carinoma correlating with the inflammatory cell changes [56]. Furthermore, Broutin et al. showed a reduction of IL-8expression in a medullary thyroid cancer-xenograft mouse model at day 1 after sunitinib treatment [18].

A similar result was found for the gene expression of MCP1 (Monocyte Chemotactic Protein 1) in the CGTH W-1 cell line. MCP-1 is a chemokine ligand associated with a more aggressive behavior in breast cancer patients [57]. Radiation therapy induced a significant elevation of the mRNA levels of MCP1. Sunitinib treatment clearly attenuated this effect in the radiation group. The ML-1 cell line showed a different behavior where we only detected a significant suppression in the expression of the $M C P 1$ gene in the combined radiation and sunitinib groups. Little is known about MCP-1 and its importance for thyroid cancer. Tanaka et al. showed in 2009, that MCP1 expression in papillary thyroid cancer induces a more aggressive behavior and metastases [58].

The tumor necrosis factor $\alpha$ (TNF- $\alpha$ ) is a cytokine involved in the extrinsic apoptosis signaling process. It plays a key role in the regulation of immune cells. TNF- $\alpha$ and matrix metalloproteinase- 9 are potential biomarkers for the sunitinib activity in patients with renal cell carcinoma [59]. Radiation induced an upregulation of TNFA in ML-1 cells, but sunitinib had no further influence on the TNFA mRNA content. A very interesting result was found for the CGTH W-1 cell line. Sunitinib induced a suppression of the TNFA gene, whereas radiation produced a significant upregulation of TNFA. Little is known about the impact of TNF- $\alpha$ in poorly differentiated thyroid carcinomas. In a phase II trial in patients with advanced and previously treated renal cell carcinoma, the monoclonal TNF- $\alpha$ antibody infliximab was used for therapy. The drug was very well tolerated and the response rate was $16 \%[60]$. 
Grosse et al.: Sunitinib and Thyroid Cancer Cells

\section{Conclusions}

Both poorly differentiated follicular thyroid carcinoma cell lines ML-1 and CGTH W-1 were investigated in this paper to evaluate the effects of sunitinib as a monotherapy or in combination with radiotherapy or radiotherapy alone.

We investigated the molecular mechanisms of the effects of sunitinib and radiation on human thyroid cancer cells. Furthermore, we used Multi-Analyte Profiling technology to measure soluble factors released by the cells in the supernatant. We have shown that sunitinib exerts a clear effect on gene expression and secretion of the cytokines IL- 6 and IL-8. A striking finding was the enhanced VEGFD expression in sunitinib-treated cells in combination with radiation in both tumor cell lines.

The different response between the cell lines might be due to age and origin of the two patients from whom the cell lines were derived, molecular changes of the thyroid tumors and the following immortalization of the cells during establishment of the cell lines. A further aspect would be the radiation exposure of the patients. For the cell line ML-1 a previous exposure to radioiodine in the course of therapy of the patient is known, while the medical history of the patient from whom the CGTH W-1 cell line was obtained is unknown. Previous exposure of the primary tumors and metastases to radiation (radioiodine and/or external beam irradiation) could have led to molecular changes in the cells.

On the molecular side general differences between the cell lines are evident. ML1 , originating from a tumor relapse, has the ability to take up iodine and/or glucose and to secret thyroglobulin. Furthermore triiodothyronine is released constitutively into cell culture supernatant. The CGTH W-1 cell line has lost these abilities. Comparing cell lines and tumor cells of origin there retain some properties concerning genetics, epigenetics and gene expression, but evident differences are obvious. As described by van Staveren et al. and Saiselet et al. [61,62] these differences might be the consequence of preselection of primary cells, dedifferentiation and Darwinian evolution in vitro. Furthermore, tumors and metastases are more heterogeneous than isolated tumor cells. A very interesting finding was the decreased secretion of soluble TNF- $\alpha$ in both cell lines after sunitinib application. In CGTH W-1 cells, the level was reduced below the detection limit. These results were mirrored by the RT-PCR results of CGTH W-1 cells.

In summary, these in vitro experiments suggest IL-6, IL-8, VEGFD and TNF- $\alpha$ as future biomarkers in thyroid cancer in the course of therapy and as clinical parameter for follow ups after thyroidectomy, histopathological confirmation of thyroid cancer and therapy with radioiodine, but these findings have to be confirmed in vivo. Because of a potential elevation of serum levels caused by inflammatory/autoimmune diseases these proteins are not suitable as screening method for patients with thyroid nodules. If a therapy with sunitinib in combination with radiation is beneficial for patients with advanced radioiodine-refractory thyroid cancer has to be proven in clinical trials.

\section{Abbreviations}

ANOVA (analysis of variance); BRAF (v-raf murine sarcoma viral oncogene homolog B1); C-kit (stem cell factor receptor); d (day); DTC (differentiated thyroid cancer); EMEA (European Medicines Agency); ERK (extracellular signal-regulated kinase); FCS (fetal calf serum); FDA (Food and Drug Administration); FLK (fetal liver kinase); FLT (fetal liver tyrosine kinase); FTC (follicular thyroid cancer); GM-CSF (granulocyte-macrophage colony-stimulating factor); IFN (interferon); IL (interleukin); KRAS (V-Ki-ras2 Kirsten rat sarcoma viral oncogene homolog); LDD (least detectable dose); MAP (Multi-Analyte Profiling); MCP (monocyte chemotactic protein); MCT (monocarboxylate transporter); MEK (Mitogen-activated protein kinases); MIP (macrophage inflammatory protein); MMP (matrix metalloproteinase); mRNA (messenger ribonucleic acid); MTC (medullary thyroid carcinoma); PCR (polymerase chain reaction); PDGFR (platelet-derived growth factor 
Grosse et al.: Sunitinib and Thyroid Cancer Cells

receptor); PTC (papillary thyroid cancer); R (irradiation); RBM (Rules-Based Medicine); $\mathrm{R}+\mathrm{S}$ (combination of irradiation and Sunitinib); S (Sunitinib); SD (standard deviation); T3 (triiodothyronine); T4 (thyroxine); TGF (transforming growth factor); TKI (tyrosine kinase inhibitor); TNF (tumor necrosis factor); VEGF (vascular endothelial growth factor); VEGFR (vascular endothelial growth factor receptor).

\section{Conflicts of Interest}

No potential conflicts of interest were disclosed.

\section{Acknowledgements}

The study was supported by DLR/BMWi Project 50WB1124 of DG. The authors like to thank Mrs. Henriette Dam for her excellent technical assistance. Moreover, we thank Dr. Jessica Pietsch for her help with the organization of the figures. Data presented in this publication are part of the Master Thesis of Elisabeth Warnke prepared during the Master educational program at Charité-Universitätsmedizin Berlin.

\section{References}

$>1$ Agate L, Lorusso L, Elisei R: New and old knowledge on differentiated thyroid cancer epidemiology and risk factors. J Endocrinol Invest 2012;35:3-9.

-2 Liao S, Shindo M: Management of well-differentiated thyroid cancer. Otolaryngol Clin North Am 2012;45:1163-1179.

3 O'Neill CJ, Oucharek J, Learoyd D, Sidhu SB: Standard and emerging therapies for metastatic differentiated thyroid cancer. Oncologist 2010;15:146-156.

-4 Durante C, Haddy N, Baudin E, Leboulleux S, Hartl D, Travagli JP, Caillou B, Ricard M, Lumbroso JD, De Vathaire F, Schlumberger M: Long-term outcome of 444 patients with distant metastases from papillary and follicular thyroid carcinoma: benefits and limits of radioiodine therapy. J Clin Endocrinol Metab 2006;91:2892-2899.

5 Baudin E, Schlumberger M: New therapeutic approaches for metastatic thyroid carcinoma. Lancet Oncol 2007;8:148-156.

6 Patyna S, Laird AD, Mendel DB, O'farrell AM, Liang C, Guan H, Vojkovsky T, Vasile S, Wang X, Chen J, Grazzini M, Yang CY, Haznedar JO, Sukbuntherng J, Zhong WZ, Cherrington JM, Hu-Lowe D: SU14813: a novel multiple receptor tyrosine kinase inhibitor with potent antiangiogenic and antitumor activity. Mol Cancer Ther 2006;5:1774-1782.

$\rightarrow 7$ Chow LQ, Eckhardt SG: Sunitinib: from rational design to clinical efficacy. J Clin Oncol 2007;25:884-896.

8 SUTENT Summary of Product Characteristics: Sutent Pfizer Limited, Kent UK, February 2012.

-9 Willhauck MJ, Schott M, Kreissl MC, Fassnacht M, Spitzweg C: New therapeutic options for advanced thyroid cancer. Dtsch Med Wochenschr 2011;136:1165-1168.

10 Carr LL, Mankoff DA, Goulart BH, Eaton KD, Capell PT, Kell EM, Bauman JE, Martins RG: Phase II study of daily sunitinib in FDG-PET-positive, iodine-refractory differentiated thyroid cancer and metastatic medullary carcinoma of the thyroid with functional imaging correlation. Clin Cancer Res 2010;16:5260-5268.

-11 Desai J, Yassa L, Marqusee E, George S, Frates MC, Chen MH, Morgan JA, Dychter SS, Larsen PR, Demetri GD, Alexander EK: Hypothyroidism after sunitinib treatment for patients with gastrointestinal stromal tumors. Ann Intern Med 2006;145:660-664.

12 Makita N, Miyakawa M, Fujita T, Iiri T: Sunitinib induces hypothyroidism with a markedly reduced vascularity. Thyroid 2010;20:323-326. 
Grosse et al.: Sunitinib and Thyroid Cancer Cells

13 Braun D, Kim TD, le Coutre P, Köhrle J, Hershman JM, Schweizer U: Tyrosine kinase inhibitors noncompetitively inhibit MCT8-mediated iodothyronine transport. J Clin Endocrinol Metab 2012;97:E100-105.

14 Schueneman AJ, Himmelfarb E, Geng L, Tan J, Donnelly E, Mendel D, McMahon G, Hallahan DE: SU11248 maintenance therapy prevents tumor regrowth after fractionated irradiation of murine tumor models. Cancer Res 2003;63:4009-4016.

15 Zeng J, Xie K, Wu H, Zhang B, Huang C: Identification and functional study of cytokines and chemokines involved in tumorigenesis. Comb Chem High Throughput Screen 2012;15:276-285.

$\checkmark 16$ Okunieff P, Chen Y, Maguire DJ, Huser AK: Molecular markers of radiation-related normal tissue toxicity. Cancer Metastasis Rev 2008;27:363-374.

-17 Rubin P, Johnston CJ, Williams JP, McDonald S, Finkelstein JN: A perpetual cascade of cytokines postirradiation leads to pulmonary fibrosis. Int J Radiat Oncol Biol Phys 1995;33:99-109.

18 Broutin S, Ameur N, Lacroix L, Robert T, Petit B, Oumata N, Talbot M, Caillou B, Schlumberger M, Dupuy C, Bidart JM: Identification of soluble candidate biomarkers of therapeutic response to sunitinib in medullary thyroid carcinoma in preclinical models. Clin Cancer Res 2011;17:2044-2054.

19 Lahdenranta J, Chung DC, Fischman AJ, Lauwers GY, Shellito P, Czito BG, Wong TZ, Paulson E, Poleski M, Vujaskovic Z, Bentley R, Chen HX, Clark JW, Jain RK: Efficacy, safety, and biomarkers of neoadjuvant bevacizumab, radiation therapy, and fluorouracil in rectal cancer: a multidisciplinary phase II study. J Clin Oncol 2009;27:3020-3026.

-20 Ning Y, Manegold PC, Hong YK, Zhang W, Pohl A, Lurje G, Winder T, Yang D, LaBonte MJ, Wilson PM, Ladner $\mathrm{RD}$, Lenz HJ: Interleukin-8 is associated with proliferation, migration, angiogenesis and chemosensitivity in vitro and in vivo in colon cancer cell line models. Int J Cancer 2011;128:2038-2049.

21 Schönberger J, Bauer J, Spruss T, Weber G, Chahoud I, Eilles C, Grimm D: Establishment and characterization of the follicular thyroid carcinoma cell line ML-1. J Mol Med 2000;78:102-110.

-22 Lin JD, Chao TC, Weng HF, Huang HS, Ho YS: Establishment of xenografts and cell lines from welldifferentiated human thyroid carcinoma. J Surg Oncol 1996;63:112-118.

23 Grosse J, Grimm D, Westphal K, Ulbrich C, Moosbauer J, Pohl F, Koelbl O, Infanger M, Eilles C, Schoenberger $\mathrm{J}$ : Radiolabeled annexin $\mathrm{V}$ for imaging apoptosis in radiated human follicular thyroid carcinomas--is an individualized protocol necessary? Nucl Med Biol 2009;36:89-98.

24 Piscazzi A, Costantino E, Maddalena F, Natalicchio MI, Gerardi AM, Antonetti R, Cignarelli M, Landriscina M: Activation of the RAS/RAF/ERK signaling pathway contributes to resistance to sunitinib in thyroid carcinoma cell lines. J Clin Endocrinol Metab 2012;97:E898-906.

25 Pohl F, Hassel S, Nohe A, Flentje M, Knaus P, Sebald W, Koelbl O: Radiation-induced suppression of the Bmp2 signal transduction pathway in the pluripotent mesenchymal cell line C2C12: an in vitro model for prevention of heterotopic ossification by radiotherapy. Radiat Res 2003;159:345-350.

26 Pohl F, Grosse J, Grimm D, Brockhoff G, Westphal K, Moosbauer J, Koelbl O, Infanger M, Eilles C, Schoenberger J: Changes of apoptosis, p53, and bcl-2 by irradiation in poorly differentiated thyroid carcinoma cell lines: a prognostic marker for the prospect of therapeutic success? Thyroid 2010;20:159-166.

-27 Poremba C, Heine B, Diallo R, Heinecke A, Wai D, Schaefer KL, Braun Y, Schuck A, Lanvers C, Bànkfalvi A, Kneif S, Torhorst J, Zuber M, Köchli OR, Mross F, Dieterich H, Sauter G, Stein H, Fogt F, Boecker W: Telomerase as a prognostic marker in breast cancer: high-throughput tissue microarray analysis of hTERT and hTR. J Pathol 2002;198:181-189.

28 Grimm D, Bauer J, Ulbrich C, Westphal K, Wehland M, Infanger M, Aleshcheva G, Pietsch J, Ghardi M, Beck M, El-Saghire H, de Saint-Georges L, Baatout S: Different responsiveness of endothelial cells to vascular endothelial growth factor and basic fibroblast growth factor added to culture media under gravity and simulated microgravity. Tissue Eng Part A 2010;16:1559-1573.

29 Ulbrich C, Westphal K, Baatout S, Wehland M, Bauer J, Flick B, Infanger M, Kreutz R, Vadrucci S, Egli M, Cogoli A, Derradji H, Pietsch J, Paul M, Grimm D: Effects of basic fibroblast growth factor on endothelial cells under conditions of simulated microgravity. J Cell Biochem 2008;104:1324-1341.

-30 Infanger M, Ulbrich C, Baatout S, Wehland M, Kreutz R, Bauer J, Grosse J, Vadrucci S, Cogoli A, Derradji H, Neefs M, Küsters S, Spain M, Paul M, Grimm D: Modeled gravitational unloading induced downregulation of endothelin-1 in human endothelial cells. J Cell Biochem 2007;101:1439-1455. 


\begin{tabular}{|c|c|c|}
\hline Cellular Physiology & Cell Physiol Biochem 2013;32:154-170 & \\
\hline and Biochemistry & $\begin{array}{l}\text { DOI: } 10.1159 / 000350132 \\
\text { Published online: July 12, } 2013\end{array}$ & $\begin{array}{l}\text { O } 2013 \text { S. Karger AG, Basel } \\
\text { www.karger.com/cpb }\end{array}$ \\
\hline
\end{tabular}

-31 Kossmehl P, Kurth E, Faramarzi S, Habighorst B, Shakibaei M, Wehland M, Kreutz R, Infanger M, J Danser AH, Grosse J, Paul M, Grimm D: Mechanisms of apoptosis after ischemia and reperfusion: role of the reninangiotensin system. Apoptosis 2006;11:347-358.

-32 Infanger M, Faramarzi S, Grosse J, Kurth E, Ulbrich C, Bauer J, Wehland M, Kreutz R, Kossmehl P, Paul M, Grimm D: Expression of vascular endothelial growth factor and receptor tyrosine kinases in cardiac ischemia/reperfusion injury. Cardiovasc Pathol 2007;16:291-299.

33 Magnusson NE, Dyrskjøt L, Grimm D, Wehland M, Pietsch J, Rungby J: Gene networks modified by sulphonylureas in beta cells: a pathway-based analysis of insulin secretion and cell death. Basic Clin Pharmacol Toxicol 2012;111:254-261.

-34 Pietsch J, Kussian R, Sickmann A, Bauer J, Weber G, Nissum M, Westphal K, Egli M, Grosse J, Schönberger J, Wildgruber R, Infanger M, Grimm D: Application of free-flow IEF to identify protein candidates changing under microgravity conditions. Proteomics 2010;10:904-913.

-35 Pietsch J, Sickmann A, Weber G, Bauer J, Egli M, Wildgruber R, Infanger M, Grimm D: A proteomic approach to analysing spheroid formation of two human thyroid cell lines cultured on a random positioning machine. Proteomics 2011;11:2095-2104.

-36 Pietsch J, Sickmann A, Weber G, Bauer J, Egli M, Wildgruber R, Infanger M, Grimm D: Metabolic enzyme diversity in different human thyroid cell lines and their sensitivity to gravitational forces. Proteomics 2012;12:2539-2346.

-37 Pietsch J, Riwaldt S, Bauer J, Sickmann A, Weber G, Grosse J, Infanger M, Eilles C, Grimm D: Interaction of proteins identified in human thyroid cells. Int J Mol Sci 2013;14:1164-1178.

-38 Chang JW, Yeh KY, Shen YC, Hsieh JJ, Chuang CK, Liao SK, Tsai LH, Wang CH: Production of multiple cytokines and induction of cachexia in athymic nude mice by a new anaplastic thyroid carcinoma cell line. J Endocrinol 2003;179:387-394.

-39 Foukakis T, Thoppe SR, Lagercrantz S, Dwight T, Weng WH, Svensson A, Höög A, Zedenius J, Wallin G, Lui WO, Larsson C: Molecular cytogenetic characterization of primary cultures and established cell lines from non-medullary thyroid tumors.Int J Oncol 2005;26:141-149.

40 Fröhlich E, Czarnocka B, Brossart P, Wahl R: Antitumor effects of arsenic trioxide in transformed human thyroid cells. Thyroid 2008;18:1183-1193.

41 Rajoria S, Suriano R, George AL, Kamat A, Schantz SP, Geliebter J, Tiwari RK: Molecular target based combinational therapeutic approaches in thyroid cancer. J Transl Med 2012;10:81.

42 Grimm D, Bauer J, Schoenberger J: Blockade of neoangiogenesis, a new and promising technique to control the growth of malignant tumors and their metastases. Curr Vasc Pharmacol 2009;7:347-357.

43 Wehland M, Bauer J, Infanger M, Grimm D: Target-based anti-angiogenic therapy in breast cancer. Curr Pharm Des 2012;18:4244-4257.

44 Pasqualetti G, Ricci S, Boni G, Tognini S, Polini A, Mariani G, Ferdeghini M, Monzani F: Off-label use of sunitinib in patients with advanced, epithelial thyroid cancer: a retrospective analysis. Recent Pat Endocr Metab Immune Drug Discov 2012;6:171-176.

45 Schmidinger M, Loidl W: Sunitinib. Arzneimittelprofil Onkol 2007;1-14.

46 Schönberger J, Grimm D, Kossmehl P, Infanger M, Kurth E, Eilles C: Effects of PTK787/ZK222584, a tyrosine kinase inhibitor, on the growth of a poorly differentiated thyroid carcinoma: an animal study. Endocrinology 2004;145:1031-1038.

-47 Nersita R, Matrone A, Klain M, Scavuzzo F, Vitolo G, Abbondanza C, Carlino MV, Giacco V, Amato G, Carella C: Decreased serum vascular endothelial growth factor-D levels in metastatic patients with differentiated thyroid carcinoma. Clin Endocrinol (Oxf) 2012;76:142-146.

48 Lai CW, Chen KY, Hung CS, Kuo SW, Chang YJ, Lin MT, Chang KC, Wu MH: Serum vascular endothelial growth factor-D levels correlate with cervical lymph node metastases in papillary thyroid carcinoma. Growth Factors 2011;29:57-62.

49 Yasuoka H, Kodama R, Hirokawa M, Takamura Y, Miyauchi A, Inagaki M, Sanke T, Nakamura Y: Neuropilin-2 expression in papillary thyroid carcinoma: correlation with VEGF-D expression, lymph node metastasis, and VEGF-D-induced aggressive cancer cell phenotype. J Clin Endocrinol Metab 2011;96:E1857-1861.

50 Burstein HJ, Elias AD, Rugo HS, Cobleigh MA, Wolff AC, Eisenberg PD, Lehman M, Adams BJ, Bello CL, DePrimo SE, Baum CM, Miller KD: Phase II study of sunitinib malate, an oral multitargeted tyrosine kinase inhibitor, in patients with metastatic breast cancer previously treated with an anthracycline and a taxane. J Clin Oncol 2008;26:1810-1816. 
51 Keefe SM, Cohen MA, Brose MS: Targeting vascular endothelial growth factor receptor in thyroid cancer: the intracellular and extracellular implications. Clin Cancer Res 2010;16:778-783.

-52 Basolo F, Fiore L, Pollina L, Fontanini G, Conaldi PG, Toniolo A: Reduced expression of interleukin 6 in undifferentiated thyroid carcinoma: in vitro and in vivo studies. Clin Cancer Res 1998;4:381-387.

-53 Chang JW, Yeh KY, Shen YC, Hsieh JJ, Chuang CK, Liao SK, Tsai LH, Wang CH: Production of multiple cytokines and induction of cachexia in athymic nude mice by a new anaplastic thyroid carcinoma cell line. J Endocrinol 2003;179:387-394.

\$54 Grosse J, Wehland M, Pietsch J, Schulz H, Saar K, Hübner N, Eilles C, Bauer J, Abou-El-Ardat K, Baatout S, Ma $\mathrm{X}$, Infanger M, Hemmersbach R, Grimm D: Gravity-sensitive signaling drives 3-dimensional formation of multicellular thyroid cancer spheroids. FASEB J 2012;26:5124-5140.

55 Porta C, Paglino C, Imarisio I, Ganini C, Sacchi L, Quaglini S, Giunta V, De Amici M: Changes in circulating pro-angiogenic cytokines, other than VEGF, before progression to sunitinib therapy in advanced renal cell carcinoma patients. Oncology 2012;84:115-122.

-56 Zhu AX, Duda DG, Ancukiewicz M, di Tomaso E, Clark JW, Miksad R, Fuchs CS, Ryan DP, Jain RK: Exploratory analysis of early toxicity of sunitinib in advanced hepatocellular carcinoma patients: kinetics and potential biomarker value. Clin Cancer Res. 2011;17:918-927.

57 Fujimoto H, Sangai T, Ishii G, Ikehara A, Nagashima T, Miyazaki M, Ochiai A: Stromal MCP-1 in mammary tumors induces tumor-associated macrophage infiltration and contributes to tumor progression. Int J Cancer 2009;125:1276-1284.

58 Tanaka K, Kurebayashi J, Sohda M, Nomura T, Prabhakar U, Yan L, Sonoo H: The expression of monocyte chemotactic protein-1 in papillary thyroid carcinoma is correlated with lymph node metastasis and tumor recurrence. Thyroid 2009;19:21-25.

-59 Perez-Gracia JL, Prior C, Guillén-Grima F, Segura V, Gonzalez A, Panizo A, Melero I, Grande-Pulido E, Gurpide A, Gil-Bazo I, Calvo A: Identification of TNF-alpha and MMP-9 as potential baseline predictive serum markers of sunitinib activity in patients with renal cell carcinoma using a human cytokine array. $\mathrm{Br} \mathrm{J}$ Cancer 2009;101:1876-1883.

60 Maisey N: Antitumor necrosis factor (TNF- $\alpha$ ) antibodies in the treatment of renal cell cancer. Cancer Invest 2007;25:589-593.

-61 van Staveren WC, Solís DY, Hébrant A, Detours V, Dumont JE, Maenhaut C: Human cancer cell lines: Experimental models for cancer cells in situ? For cancer stem cells? Biochim Biophys Acta 2009;1795:92103.

62 Saiselet M, Floor S, Tarabichi M, Dom G, Hébrant A, van Staveren WC, Maenhaut C: Thyroid cancer cell lines: an overview. Front Endocrinol (Lausanne) 2012;3:133. 